\title{
QUE EL MUNDO SEA OTRO, AUNQUE PAREZCA EL MISMO
}

Sobre Nadia Isasa. Boab. Rosario: Baltasara Editora, 2020. $144 \mathrm{pp}$.

El Boab es el nombre de la flor del baobab y es, también, el nombre que Nadia Isasa (Rosario, 1979) eligió como título de su primer libro de cuentos, que ganó la Convocatoria Editorial 2019 del sello rosarino Baltasara y que se publicó entre enero y febrero de 2020.

El baobab crece en planicies arenosas y retiene el agua en su tronco; de allí, su carácter sagrado. Sólo lxs sabixs pueden recoger sus flores y sus frutos no caen lejos del árbol madre, que los reabsorbe. Sin embargo, los frutos caen: pueden reconocerse como parte de un sistema familiar que los contiene y, al mismo tiempo, elegir otro camino, sin dejar de honrar sus raíces. "La claridad perturba porque puede verse todo", dice la narradora de 'Lo verde llano se abulta' —el primer cuento del libro-y la frase puede leerse como clave de todos los textos: las protagonistas de estas historias van a enfrentarse, cada una a su modo, a esa claridad que no necesitará disfrazarse de epifanía ni de gran revelación, podrá ser apenas un destello. $\mathrm{Y}$ en esa instancia, tendrán la posibilidad de dar un salto para torcer el rumbo o dejarse 
absorber, como la flor del baobab, por la herencia y por la tradición.

Cinco relatos constituyen este libro. En los tres más extensos ('Lo verde llano se abulta', 'Partículas en el aire' y 'Una encarnadura en pena'), además de percibirse, como veremos, rasgos de estilo similares, puede leerse la Historia en la historia: el contexto histórico está allí y provoca, en parte, el conflicto que atraviesan los personajes aunque no lo determina. Los otros dos relatos ('Boab' y 'Cartón mal pintado') pueden pensarse escindidos del referente histórico puesto que allí la narración enfoca — con lente de aumentoconflictos internos de las protagonistas.

'Lo verde llano se abulta' se organiza en siete secuencias narrativas. En la primera, Amparo y el perro que la sigue encuentran el cadáver de un hombre al costado de la ruta. No es un muerto cualquiera: tiene la cara desfigurada por un balazo a quemarropa. El descubrimiento altera la rutina que desde el comienzo ("Todas las mañanas igual", p. 19) se percibe como monótona. "Los pueblos de la llanura son así, encerrados en el campo. (...) Se decían muchas cosas, pero después nadie sabía nada, nunca" (p. 22). Amparo decide entonces seguir su camino como si no hubiera visto nada. Es, sin embargo, su cuerpo el que se rebela y la obliga a alterar el orden aparente de las cosas: después de su jornada de trabajo, vuelve a su casa, con su tía, y vuela de fiebre. Su detenerse coincide con el regreso al pueblo de una amiga de la infancia que escapa de la ciudad porque allí "ya no se puede estar" ( $p$. 24). La Historia se filtra, a partir de aquí, en la historia: Amparo ya no puede volver al camino como si nada hubiera 
ocurrido y se convierte en la fuerza que se activa para enfrentar el statu quo que se despliega en dos planos: el social y el íntimo. Como en todos los enfrentamientos que se producen entre fuerzas desiguales, el triunfo de Amparo contra su propio statu quo será, también, una derrota.

'Boab' es el segundo cuento del libro. Narrado en primera persona, sumerge a lxs lectorxs en un universo más íntimo.

"Camino por Avenida Pellegrini, después de una visita a mi única abuela viva, en este otoño tropical que no comienza nunca, a la vez que descubro una compulsión que heredé de las mujeres de mi familia: guardar envases descartables." (p. 49)

Con el ritmo y el tono del fluir de la consciencia, el relato enlaza el descubrimiento con la historia familiar, el escenario de la ciudad y la "mitología" en torno a los baobabs. El primer descubrimiento desencadena otro, que incomoda, y que lleva a la narradora a ponerse en movimiento. La claridad aquí no requerirá un gesto épico: una vez que se ha reconocido la lógica del sistema familiar que se repite como herencia, bastará "acelerar un poco las cosas para romper el ciclo", para caer, sí, pero lejos del árbol.

En 'Cartón mal pintado', Eva ya está en movimiento: su madre ha muerto y ella maneja por la autopista hacia Rosario. En la "división de tareas" post-mortem, le ha tocado desarmar el departamento de su madre. "Su corazón es una caja de lombrices. No entiende cómo se siente, no sabe cómo debería sentirse" (p. 61). Intenta convencerse de que podrá hacer "lo debido" con cierta rapidez. Sin embargo, a medida que ingresa en ese universo conocido y, a la vez, ajeno, reconoce las 
huellas que el pasado familiar ha dejado impresas en ella, a pesar de la distancia. Eva logra transitar la experiencia sin que los objetos lleguen a tocarla hasta que abre el freezer y encuentra un tupper con guefilte fish: un plato que su madre elaboraba con la esperanza de recuperar y de refundar la tradición en esa familia desmoronada. El esclarecimiento puede ser apenas un destello. Y alcanza.

"Aún el olor a fósforo quemado y a café vertebra mis sentidos" es la primera frase de 'Partículas en el aire'. Organizado en secuencias claramente delimitadas y narrado, como 'Boab', en primera persona, es el olfato el sentido que permite recuperar la historia: la narradora pivota entre su universo afectivo - el que construyó en torno a unxs abuelxs que ocuparon el rol de unxs padrxs ausentxs- y el que ha vivido en la escuela a la que asistía como pupila, espacio que funciona en el relato como "pequeño mundo" que reproduce el mismo autoritarismo — los mismos dobleces, la misma doble moral- que se respiraba extramuros. La narradora es, como en el primer relato, la fuerza que se activa: su gesto es épico en términos de gesta personal y marca, a partir de ese momento, una suerte de supervivencia "enderezada a fuerza de afecto, casi desde el principio" (p. 103).

El último relato, 'Una encarnadura en pena' es quizás el que se inscribe más explícitamente en la Historia. Alma acaba de mudarse a un pueblo con su hija, mientras su pareja (Raicho) ha pasado a la clandestinidad. La ausencia de sus gatos será en el texto el factor que desencadene el conflicto de la protagonista. Es, en realidad, la gota que rebalsa el vaso: es lo que la obliga a reconocer que esa vida que lleva no tiene, para 
ella, sentido sin él; que ya no puede (ni quiere) sostener ese universo en el que la lucha es prioridad (y no ella) y que no puede (ni sabe) qué hacer al respecto.

"La madrugada le devuelve a Alma aquella fragancia pinchuda que la despierta. A través del mosquitero de la ventana entornada, se asoma el horizonte, una melodía estampada en la noche. Acerca la oreja a la abertura, deseando otra vez ese murmullo transparente que la guarece. En cambio, arriba con furia un minúsculo silencio cremoso que la ahoga [...] El calor empalagoso y el oscuro ronroneo apenas le permiten permanecer sentada en el catre tijera de lona verde". (pp. 121-122)

La profusión de sinestesias da cuenta de lo hostil que se ha vuelto el mundo para Alma: todo se ha trastocado adentro y afuera. Los gatos, finalmente, aparecerán —el fruto no cae muy lejos del árbol, pero cae- y el conflicto más profundo quedará al descubierto.

Tanto la perspectiva del narrador omnisciente como la organización en secuencias narrativas, permiten, en este relato, la narración de eventos simultáneos. Por ello, lxs lectorxs tendremos acceso a una parte de la historia que la protagonista ignorará y que cerrará, para nosotrxs, la historia con una certeza perturbadora, quizás tan perturbadora como la misma claridad.

En el prólogo de esta primera edición, dice Luisa González: "Como las flores del árbol africano, cada historia despide un delicado aroma, suave pero intenso, que intuye y comprende los contrasentidos de la vida. [...] Sin pretensiones, sin 
justificaciones, nos hace salir de la lectura, perturbados por el prodigio de la narración" (p. 12).

El estilo de Isasa, la forma en la que su mirada se cifra en las percepciones y se disparan, siempre, más allá, es consecuente con la frase en la que anclamos esta lectura: si la claridad perturba porque puede verse todo, quizás no sea necesario echar mano a recursos pirotécnicos que pongan de manifiesto el artificio. Alcanza con una escritura diáfana, sencilla, que "dice lo que dice y además más y otra cosa"1 porque de lo indecible también está hecho el lenguaje.

Como hemos visto, ninguna de las protagonistas de estos relatos saldrá ilesa del esclarecimiento, tampoco se dejará cegar. Si "lo llano se abulta", será necesario desbaratarlo todo: hurgar en las raíces para establecer la distancia respecto del árbol-madre que tenderá a reabsorbernos, para poder lidiar con la flor. Las protagonistas no sales ilesas de esa experiencia; lxs lectorxs, tampoco. Y quizás esa sea una de las pocas cosas que seguimos pidiéndole a la literatura y que este libro ofrece: hacer que el mundo que habitamos después de la lectura sea otro, aunque parezca el mismo.

\footnotetext{
${ }^{1}$ Pizarnik, Alejandra. "La palabra que sana". El infierno musical (1971).
} 